\title{
PRINCIPAIS BENEFÍCIOS AOS TRABALHADORES INFORMAIS ATRAVÉS DA FORMALIZAÇÃO COMO MICROEMPREENDEDOR INDIVIDUAL NO MUNICÍPIO DE SOBRAL
}

Leon Torres ${ }^{1}$

Monique Trévia ${ }^{2}$

Eduardo Dias ${ }^{2}$

\footnotetext{
${ }^{1}$ Outros

${ }^{2}$ Universidade Estadual Vale do Acaraú
} 


\section{PRINCIPAIS BENEFÍCIOS AOS TRABALHADORES INFORMAIS ATRAVÉS DA FORMALIZAÇAO COMO MICROEMPREENDEDOR INDIVIDUAL NO MUNICÍPIO DE SOBRAL}

\section{Resumo}

O Microempreendedor Individual é uma forma inovadora de inclusão de profissionais no mercado formal, garantindo benefícios a um custo menor de impostos. Sendo assim, o presente estudo teve como objetivo analisar quais os principais benefícios que os trabalhadores informais recebem através da formalização como microempreendedor individual. Para tanto, realizou-se uma pesquisa exploratória, com o uso de material bibliográfico e levantamento de dados através de questionário aplicado a 70 Microempreendedores Individuais localizados no município de Sobral. Os resultados demonstram que grande parte dos microempreendedores individuais são mulheres, a maioria com ensino médio completo e faturamento mensal entre 4001 a 5000 reais e dentre os principais benefícios da formalização das empresas foram a cobertura previdenciária. Pode-se observar que a principal objetivo do programa (MEI) lançado pelo governo vem dando êxito, formalizando o grande número de informais, ficando evidente no município de sobral pelo grande número de microempreendedores cadastrados no últimos anos.

Palavras-chave: Informalidade. MEI. Perfil do MEI. Empreendedorismo. 


\section{Introdução}

A categoria de microempreendedor individual foi criada para beneficiar pessoas que trabalham informalmente por conta própria, em geral são profissionais autônomos que prestam serviços simples como sapateiros, manicures, barbeiros, costureiras, pintores, mecânicos, encanadores, serralheiros, marceneiros, professores de idiomas e também no segmento do comércio como comerciante de artigos de vestuário e acessórios, merceeiro, lanchonetes, entre outros.

Para aderir ao programa é necessário que o faturamento anual do empreendedor não ultrapasse $\mathrm{R} \$ 60.000,00$, e que o mesmo não participe como sócio ou titular de outra empresa (AMARAL, 2012).

Além da formalidade, o empreendedor conta com alguns benefícios ao aderir ao programa de microempreendedor individual. Ele conta com cobertura previdenciária; pode contratar até um funcionário; isenção de taxas para abertura da empresa; acesso a serviços bancários, inclusive crédito; redução da carga tributária; pode emitir seu alvará pela internet; além de poder contar com a ajuda do Serviço Brasileiro de Apoio às Micro e Pequenas Empresas (SEBRAE) na disposição do seu negócio (OLIVEIRA, 2014).

Todos esses benefícios por um pequeno custo, o empreendedor contribui apenas com um valor máximo mensal de R \$50,00, dependendo da atividade. Sem mencionar que a formalização não tem custo algum. Fica dispensado da contabilidade formal, tendo apenas que fazer um relatório mensal das receitas que obteve no mês anterior e anualmente fazer a declaração DASN-SIMEI, no site da Receita Federal (AMARAL, 2012).

Ressalta-se que desde sua implantação o programa vem crescendo a cada ano e elevando o número de microempreendedores formalizados, que tem se mostrado não apenas uma importante ferramenta para saída da informalidade, mas também uma relevante ferramenta de entrada para o empreendedorismo.

Dentro deste contex to o presente estudo tem como objetivo analisar quais os principais benefícios que levam os trabalhadores informais à se formalizarem como microempreendedor individual (MEI). E como objetivos específicos: identificar qual o perfil do microempreendedor individual no município de Sobral-CE; identificar as vantagens proporcionadas ao microempreendedor individual após a adesão à Lei Complementar 128/2008.

Justifica-se este trabalho pela relevância de se conhecer as vantagens e benefícios que a formalização pode trazer para os trabalhadores informais. O estudo é importante para a sociedade que desfruta do trabalho destas pessoas, para o município que é um comprador de mercadorias e serviços, para as empresas que necessitam estar em dia com o fisco. É também relevante para os acadêmicos, de forma que é um projeto recente do governo e pode ser alvo de várias discussões acerca do assunto, já que tem o objetivo de diminuir o desemprego do país, dando aos trabalhadores benefícios significativos tais como benefício previdenciário, carga

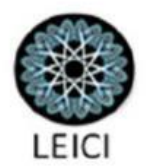


tributária reduzida, contratação de um funcionário com menor custo, entre outros. Muitos trabalhadores ainda não se formalizaram, pois não tem conhecimento da figura de pessoa jurídica do Microempreendedor Individual e de suas vantagens comparado aos trabalhadores informais.

Nesse contexto questiona-se: quais os principais benefícios que levam os trabalhadores informais a se formalizarem como microempreendedores individuais (MEI)?

\section{Referencial Teórico}

\subsection{Empreendedorismo}

Durante as últimas duas décadas percebe-se uma crescente expansão de conhecimentos sobre o tema empreendedorismo, diante da importância do mesmo no contexto da economia atual do Brasil. Segundo Dornelas (2008) a transformação e implementação de ideias em oportunidades com o envolvimento de pessoas e processos leva à criação de negócios de sucesso, é uma das definições que mais atende o conceito de empreendedorismo. Com isso, propulsiona a criação de novos empreendimentos no mercado, que aumenta a rentabilidade, gera mais empregos e ajuda o crescimento do país.

Oliveira (2014, p. 4) afirma que "O termo empreendedorismo foi idealizado, em 1949, pelo economista Joseph Schumpeter (1983-1950), designando a situação de um executivo de empresa com elevada criatividade [...]" Nessa época, Joseph correlacionou o conceito de empreendedorismo ao do profissional focado na criatividade e inovação tecnológica.

Baseado em Dornelas (2008, p. 14), “[...] o movimento no Brasil começou a tomar forma em 1990, quando entidades como SEBRAE (Serviço Brasileiro de Apoio às Micro e Pequenas Empresas) e Softex (Sociedade Brasileira para Exportação de Software) foram criadas".

No caso brasileiro, as motivações para a popularidade do termo empreendedorismo eram a criação de pequenos empreendimentos e diminuição de taxas da mortalidade das mesmas. O SEBRAE é um dos órgãos mais conhecidos designado ao pequeno empresário brasileiro, que busca o suporte para a criação da empresa. Já a entidade Softex foi inventada para levar as empresas de software ao mercado externo.

O empreendedor é uma figura importante para o desenvolvimento da economia de um país, em qualquer modelo econômico. Segundo pesquisa Global Entrepreneurship Monitor (GEM) 2014 o Brasil ocupa a primeira posição no ranking mundial em número de empreendedores, à frente de nações como China, Estados Unidos, Reino Unido, Japão e França. O Nordeste, dentre as cinco regiões do Brasil, é a mais empreendedora, com uma taxa total de $36,4 \%$, que representa empreendedores estabelecidos e iniciais com faixa etária de 18 a 64 anos.

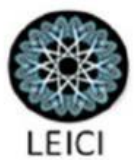


O índice é superior à média brasileira, que é $34,5 \%$. Isso significa que um terço da população possui um negócio próprio.

Baseado em Hisrich, Peters e Shepherd (2009, p. 36), "O papel do empreendedorismo no desenvolvimento econômico envolve mais do que apenas o aumento de produção e de renda per capita; envolve iniciar e constituir mudanças na estrutura do negócio e da sociedade".

Atualmente o Brasil apresenta obstáculos no ambiente de inserção ao mercado de trabalho, diante às dificuldades de encontrarem um emprego ou manterem-se no mercado de trabalho, os empreendedores optam por abrir um pequeno negócio, assim iniciam por necessidade e não por perceberem uma oportunidade. Os empreendedores por oportunidade são motivados pela percepção de uma opção rentável de negócio, já os empreendedores por necessidade são motivados pela falta de alternativa satisfatória de trabalho (Global Entrepreneurship Monitor, 2014).

Os empreendedores que abrem seu próprio negócio por necessidade são aqueles que, na sua visão, não possuem opções de trabalho, está desempregado, e para continuar com o seu sustento e sustento de sua família, se aventuram em abrir um negócio próprio, na maioria das vezes sem nenhum planejamento (GUARIDO FILHO; MACHADO-DA-SILVA, 2014).

Os empreendedores que abrem suas empresas por necessidade tendem ao fechamento, pois não fazem um planejamento adequado e não inovam. Diante disso, acabam perdendo seu espaço no mercado, não conseguindo se manter por muito tempo no mesmo. Aproximadamente metade das empresas fecha em três anos, conforme dados do IBGE (Instituto Brasileiro de Geografia e Estatística). Vale ressaltar que não é regra todas as empresas abertas por necessidade fecharem, assim como as abertas por oportunidade serem bem sucedidas. Aquele empreendedor que estuda, procura sempre se atualizar, inova e constantemente busca mais conhecimento na área terá maiores probabilidades de sucesso no seu negócio.

Em contrapartida a os empreendedores por oportunidades, mesmo quando possuem outras opções de emprego, optam por iniciar um novo negócio, eles sabem onde querem chegar, fazem um planejamento prévio, tem em mente o que querem buscar para a empresa e visa à geração de lucros, empregos e riquezas, este por sua vez, se encaixa melhor em nossa visão do que é ser um empreendedor (CORDEIRO, 2010).

\subsection{Economia Informal no Brasil}

A informalidade assume diferentes significados, costuma variar de acordo com os interesses de cada segmento social. Segundo Cleps (2009), a sonegação fiscal, comércio de rua ou ambulantes, evasão, contratação ilegal de trabalhadores assalariados, terceirização, trabalhar avulso, trabalho em domicílio, trabalho temporário, entre outros, são acontecimentos distintos que podem representar o termo informal.

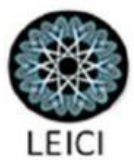


Para Dornelas (2008, p.28), pode descrever o setor informal como sendo unidades econômicas, dos quais se destacam o fato de o detentor exercer as funções de patrão e empregado simultaneamente e de não existir separação entre as atividades de gestão e produção. Para tanto, os trabalhadores, que por apresentarem dificuldades de retornar ou ingressar ao mercado de trabalho, ou até mesmo por escolha, usaram como significado de trabalho informal o auto emprego, pois obtêm renda através de formas de trabalho por conta própria.

Segundo Feijó e Silva (2009, p.333), os diversos grupos que constituem a economia informal necessitam apresentar pelo menos duas características: não devem ser reconhecidos ou protegidos por lei ou regulamentação e tanto os empregados quanto os empregadores são caracterizados por um alto grau de vulnerabilidade.

Nesse contexto, a alternativa cada vez mais presente no mercado de trabalho é trabalhar por conta própria. Estes trabalhadores informais atuam suas atividades de inúmeras formas: manicures, cabeleireiros, costureiras, artesãos, entre outros.

Com a implantação de projetos e estudos que visem combater a informalidade, os impactos da economia informal no país podem ser minimizados. Segundo Pastore (2010, p.10), a simplicidade tem de ser a coluna dorsal das novas instituições do trabalho. O Brasil realizou duas experiências para combater a informalidade e para ampliar a formalização: a criação da Lei das Microempresas e das Empresas de Pequeno Porte "SIMPLES" através da Lei no 9.317 de 05 de dezembro de 1996 e a Lei n ${ }^{\circ} 9.601$ de 21 de janeiro de 1998 (contrato de trabalho por prazo determinado). De acordo com Pastore (2010, p.10), para abranger um número maior e mais significativo de trabalhadores informais estas experiências poderiam ser ainda mais simplificadas.

Diante dessa realidade, visando diminuir o trabalho informal no Brasil, o governo brasileiro adotou medidas para abrandar a situação da informalidade no Brasil. Por meio de estudos e aperfeiçoamento da legislação ou até mesmo programas de apoio a estes trabalhadores, surgiu assim o Empreendedor Individual, que oferece a oportunidade de formalizar estes trabalhadores informais sem burocracia.

Conforme o levantamento de dados da PNAD em 2009 no Brasil, a taxa de informalidade por setor mostra que nas regiões não metropolitanas a informalidade é mais elevada que nas regiões metropolitanas em alguns setores da economia, sendo: Indústria de construção com 48,6\% (quarenta e oito vírgula seis por cento), Comércio com 30,2\% (trinta vírgula dois por cento) e Serviços com 53,8\% (cinquenta e três vírgula oito por cento).

Em 2005 o SEBRAE divulgou um relatório sobre a Economia Informal Urbana. De acordo com SEBRAE (2005, p.5) este relatório tem como propósito contribuir para uma difusão dos dados da economia informal no Brasil, para incentivar análise e debates sobre a situação dos empreendimentos informais no Brasil e estimular o surgimento de políticas públicas com vista à diminuição da informalidade na economia brasileira. 
O relatório sobre a economia informal urbana analisou temas como: dificuldades, números de trabalhadores informais, entre outros, com o objetivo de obter dados e informações para que o governo busque alternativas e soluções para que estes profissionais se formalizem.

\subsection{Contexto do Microempreendedor Individual}

A Lei Complementar 123 de 14 de dezembro de 2006, conhecida como à Lei Geral das Micro e Pequenas Empresas trouxeram tratamentos diferenciados e favorecidos para as MEs e EPPs no cenário nacional. Baseada nos artigos, 170 e 179 da Constituição Federal de 1988, esta LC trouxe vantagens e melhorias para a MPEs, nesse sentido algumas alterações foram feitas ao longo do tempo com o intuito de dar ainda mais força para essas categorias de empresas, alterações estas que se deram através das Leis Complementares 127/07, 128/08, respectivamente, tendo como ápice a criação e regulamentação do Empreendedor Individual EI, na LC 128/08.

A legislação trouxe vários benefícios para as MPEs, facilitou o regime de recolhimento dos impostos e contribuições da União, dos Estados, do Distrito Federal e dos Municípios, inclusive com simplificação das obrigações fiscais acessórias através do supersimples, houve uma desoneração tributária das receitas de exportação, substituição tributária, tributação monofásica e ICMS antecipado com encerramento de tributação, foi concedido suspenção de algumas obrigações trabalhistas e previdenciários, facilitou ainda a simplificação na abertura, alteração e encerramento das MPEs, permitiu a abertura da empresa na residência, facilitou o acesso ao crédito e ao mercado, deu preferencias nas vendas para o poder público, criou estímulos para a inovação, proporcionou o incentivo ao associativismo na formação de sociedades de propósitos específicos, para aumentar os negócios, regulamentou o Microempreendedor Individual, criando condições favoráveis para sua formalização com benefícios previdenciários.

Conforme Lopes Junior e Matias (2011), MEI é o trabalhador autônomo informal ou que possui um pequeno negócio, sendo necessário um faturamento de até $\mathrm{R} \$ 60$ mil no ano calendário anterior (valor atualizado em janeiro de 2011), ou seja, com uma média de $\mathrm{R} \$$ 5.000,00 reais por mês. Caso ultrapasse o referido saldo será desenquadrado do programa MEI e enquadrado no Simples Nacional. Esse empresário individual pode economizar no pagamento de impostos e garantir ao mesmo tempo a acessibilidade aos benefícios e facilidades.

O microempreendedor individual pode atuar no comércio em geral, indústria em geral e serviços de natureza não intelectual/sem regulamentação legal. O MEI será enquadrado no Simples Nacional e terá vários tributos federais isentos, o imposto de renda de pessoa jurídica, PIS, Confins, IPI e CSLL, contribuição para o sistema S, nesse sentido o MEI irá contribuir para a sua própria previdência, além do imposto estadual ICMS no caso de exercer atividade de comércio ou indústria, o imposto municipal ISS para a atividade de serviço e contribuirá com

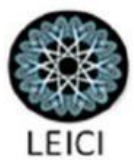


os dois impostos caso exercer uma atividade mista, comércio ou indústria e serviço, o valor mensal de acordo com a atividade que exerça conforme tabela:

Tabela 1 - Recolhimento do microempreendedor individual

\begin{tabular}{ccccc}
\hline Atividades & INSS & \multicolumn{2}{c}{ Impostos } & Total \\
\hline & $\mathbf{5 \%} \boldsymbol{S M})$ & ICMS & ISS & \\
\hline Indústria & $\mathrm{R} \$ 47,70$ & $\mathrm{R} \$ 1,00$ & - & $\mathrm{R} \$ 48,70$ \\
Comércio & $\mathrm{R} \$ 47,70$ & $\mathrm{R} \$ 1,00$ & - & $\mathrm{R} \$ 48,70$ \\
Serviços & $\mathrm{R} \$ 47,70$ & - & $\mathrm{R} \$ 5,00$ & $\mathrm{R} \$ 52,70$ \\
Mista & $\mathrm{R} \$ 47,70$ & - & $\mathrm{R} \$ 6,00$ & $\mathrm{R} \$ 53,70$ \\
\hline
\end{tabular}

Fonte: Autoria própria (2018).

É importante ressaltar que o valor total da contribuição desse empresário pode aumentar conforme o salário mínimo, segundo a legislação vigente, tendo em vista que a contribuição do INSS é sobre o salário mínimo.

De acordo com a cartilha do MEI SEBRAE de 2018, mais de 500 atividades podem ser enquadradas como microempreendedor individual, os profissionais com atividades mais atuantes e que podem se tornar empreendedores individuais são: baleiro, bar, lanchonete, comercio de bebidas, vestuário, acessórios, artesão, borracheiro, chaveiro, cabeleireiro, costureira, depiladora, eletricista, manicure, pedreiro, pipoqueiro, salão de beleza, entre outros (COSTA, 2018).

O microempreendedor individual pode funcionar de várias formas, desde um ponto fixo, até na Internet, podendo também ser ambulante, porém para exercer a atividade como ambulante o empresário irá necessitar de uma autorização prévia da prefeitura para poder vender suas mercadorias nos locais permitidos pela lei municipal.

Ainda como forma de acessibilidade a inúmeros benefícios oferecidos, o cadastramento do empreendedor individual é feito pela internet através do portal do empreendedor e o processo do registro é simples e seguro, sem a necessidade de um contador ou especialista para traduzir manuais técnicos de difícil entendimento para o iniciante (ARAÚJO, 2014). A emissão dos boletos para serem pagos é através do mesmo portal de forma simples e intuitiva, essa característica do MEI é muito assertiva quando se refere à redução da burocracia.

Baseado em César et al (2012), o empresário possui diversos benefícios desde o ato da formalização e informações gratuitas, possuindo também o benefício que é a cobertura previdenciária. Essas coberturas auferidas pelo MEI são as mesmas dos que contribuem individualmente. Cobertura previdenciária para o empreendedor e sua família (auxilio doença, aposentadoria por idade, salário maternidade após carência, pensão por morte e auxilio reclusão). 
Para os empreendedores registrados no programa do microempreendedor individual serão obrigados à emissão de notas fiscais avulsas nas vendas e nas prestações de serviços para pessoas jurídicas; o preenchimento manual do relatório mensal da receita bruta que deve ser anexada junto às notas fiscais; deve-se realizar todo ano a declaração do valor do faturamento do ano anterior até o dia 31 de maio para evitar multas (PORTAL DO EMPREENDEDOR, 2018).

O microempreendedor individual tem grande importância para o desenvolvimento social do país, tendo em vista a retirada de milhões de pessoas da informalidade, gerando com isso garantias previdenciárias que serão úteis no futuro desses empresários individuais, fazendo com que esse público se beneficie no ato da necessidade de alguns dos benefícios cobertos pela previdência social, com o recolhimento do MEI (SOUZA, 2013).

Possuidor de grandes oportunidades competitivas dentro do mercado comerciário como possibilidade de crescimento em um ambiente seguro como empreendedor, desempenhando a atividade de forma legal. E, depois de realizado todos os procedimentos mencionados acima, a empresa está devidamente legalizada e formalizada e apta a exercer suas atividades empresariais e utilizar de benefícios proporcionados ao MEI.

\section{Metodologia}

A pesquisa tem como procedimento inicial a identificação de um problema, finalizando com a resposta deste. Segundo Gil (2010), o objetivo fundamental de uma pesquisa é descobrir respostas para problemas mediante o emprego de procedimentos científicos. Este trabalho caracterizou-se como de caráter exploratório com natureza quantitativa.

Para Gil (2010), a pesquisa exploratória tem como objetivo proporcionar maior familiaridade com o problema, com vistas a torná-lo mais explícito ou a construir hipóteses. A grande maioria dessas pesquisas envolve: (a) levantamento bibliográfico; (b) entrevistas com pessoas que tiveram experiências práticas com o problema pesquisado; e (c) análise de exemplos que estimulem a compreensão. Essas pesquisas podem ser classificadas como: pesquisa bibliográfica e estudo de caso.

Para a produção do presente artigo primeiro foi feito um levantamento de informações e assim foi desenvolvido o referencial teórico do trabalho, com o objetivo de fundamentar a pesquisa, que teve embasamento em livros, artigos, cartilhas, periódicos e sites sobre os 
referidos temas: empreendedorismo, economia informal e o contexto sobre microempreendedor individual, além da base conceitual para a formação de um dispositivo de coleta de dados.

A população total de empresas inscritas no SIMEI-Sobral, local de pesquisa deste estudo é de 4.184, porém o estudo compreendeu uma amostragem aleatória 70 microempreendedores individuais do município de Sobral dos segmentos de serviços, indústria e comércio, que formalizaram suas atividades conforme a Lei Complementar 128/08 em vigor, através de pesquisa direta realizada pela pesquisadora no SEBRAE-Ce. Os dados foram coletados no período de 10 de outubro à 13 de dezembro de 2017.

O planejamento da pesquisa resultou em duas etapas; sendo a primeira etapa voltada para a aplicação dos questionários com os microempreendedores individuais, a fim de caracterizar o perfil e identificar quais benefícios proporcionados ao microempreendedor individual estão levando os trabalhadores informais a se formalizarem e, a segunda etapa voltou-se para análise e interpretação dos dados com o auxílio do software Statistical Package for the Social Sciences (SPSS) versão 21.0 e do excel.

\section{Resultados E Discursões}

Com a aplicação do questionário, obteve-se um total de 70 respondentes. Fez-se necessária, então, uma análise detalhada dos dados para a construção de um estudo de caráter investigativo como este se propõe. Partindo disso, foi possível entender melhor as razões que explicam o universo dos microempreendedores pesquisados e o porquê das respostas. Esta primeira parte da investigação, entretanto, teve a intenção de traçar um perfil para o públicoalvo estudado partindo de perguntas objetivas e pessoais sobre os mesmos.

\subsection{Perfil Social Econômico dos Participantes}

Nas respostas da questão que trata sobre o gênero dos microempreendedores pesquisados, percebeu-se a predominância do sexo feminino que participaram da pesquisa $(56 \%)$ confirmando o que a literatura comentava a respeito da "onipresença" das mulheres no setor de comércio informal.

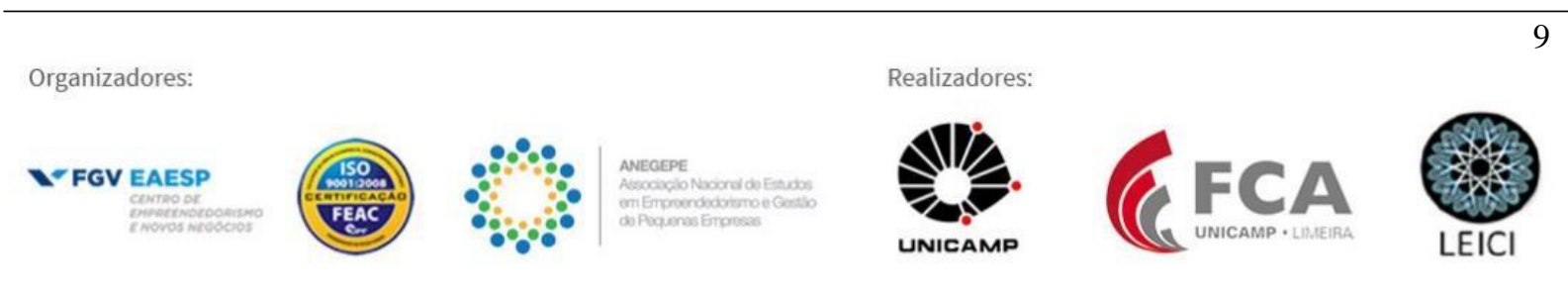


Segundo artigo publicado on line as mulheres estão empreendendo com toda força no setor do comércio (42\%), (39\%) nos serviços e (18\%) na indústria. As atividades preferidas pelas mulheres são: Comércio de artigos de vestuário (17,4\%), serviços de cabeleireiros e atividades de estética $(17,1 \%)$. Quanto ao público masculino, a participação maior é na construção civil e no comércio varejista de artigos de vestuário e acessórios (FAGUNDES, 2014).

Com o objetivo de traçar um perfil desse público, perguntou-se o grau de escolaridade alcançado por cada microempreendedor a fim de identificar nível de formação dos mesmos. A maior incidência é a de pessoas com o ensino médio, com $61 \%$ dos respondentes. Percebeu-se também pessoas com escolaridade Superior, com $24 \%$. Nota-se também maior incidência de pessoas com escolaridade completa em relação aos incompletos para cada nível proposto, seja ele o fundamental, o médio ou o superior, o que evidencia, de certa forma, a boa escolaridade dos respondentes, apesar de que a função como microempreendedor não exigir a escolaridade como pré-requisito.

Em relação ao faturamento mensal pelos microempreendedores individual a maioria dos pesquisados (30\%) relataram faturar entre 4001 a 5000 mil reais seguindo com $25 \%$ quem fatura entre 3001 à 4000. No caso as respostas da pesquisa estão de acordo com o que versa o perfil do Micro empreendedor Individual onde a receita bruta anual (de janeiro a dezembro) do MEI não poderá ultrapassar R \$ 60.000,00 ou seja 5.000,00 por mês. Caso o MEI se formalize no decorrer do ano, a receita bruta de $\mathrm{R} \$ 60.000,00$ será proporcional aos meses após formalização.

4.2 Atributos determinantes dos principais benefícios aos trabalhadores informais através da formalização como microempreendedor individual.

Tabela 1. Local que exerce seu negócio

\begin{tabular}{lc}
\hline \multicolumn{1}{c}{ Características } & $\mathbf{( \% )}$ \\
\hline Minha residência & $38 \%$ \\
Estabelecimento comercial & $22 \%$ \\
Ambulante & $30 \%$ \\
Em domicilio & $10 \%$ \\
\hline Total & $\mathbf{1 0 0 \%}$ \\
\hline
\end{tabular}

Fonte. Autoria Própria (2017). 
Quanto à escolha da localização para o funcionamento do negócio, de acordo com a tabela 1, do total dos MEI, os números indicaram que 38\% atuam em sua própria casa, sendo que $22 \%$ em um estabelecimento comercial; $30 \%$ são ambulantes. A facilidade para formalização permite que o empreendedor trabalhe em casa para realizar suas atividades, o que permite a isenção de despesas com aluguel e transporte.

Tabela 2. Sua principal ocupação antes de se registrar como MEI

\begin{tabular}{l|c}
\hline \multicolumn{1}{c|}{ Características } & $\mathbf{( \% )}$ \\
\hline Desempregado(a) & $7 \%$ \\
Empregado(a) sem carteira assinada & $10 \%$ \\
Empregado(a) com carteira assinada & $20 \%$ \\
Negócio próprio e já era formalizado & $0 \%$ \\
Negócio há 2 anos ou menos, mas era informal & $6 \%$ \\
Negócio entre 2 e 5 anos, mas era informal & $21 \%$ \\
Negócio há mais de 5 anos, mas era informal & $36 \%$ \\
\hline Total & $\mathbf{1 0 0 \%}$ \\
\hline
\end{tabular}

Fonte. Autoria Própria (2017).

Antes de se formalizar, de acordo com a tabela 2, 20\% dos microempreendedores individuais, eram empregados de carteira assinada; $10 \%$ eram microempreendedores informais (sem carteira assinada); 7\% desempregado; 6\% tinham negócio há 2 anos mas era informal; $21 \%$ entre 2 a 5 anos mas eram informal e $36 \%$ há mais de 5 anos mas também informal.

Com esse resultado pode-se concluir que grande parte dos empreendedores apenas se formalizou, mas já exerciam a mesma atividade de maneira informal. Sendo assim, o programa do governo está conseguindo levar os microempreendedores a formalidade.

Tabela 3. Após registrado como MEI, solicitou financiamento bancário em nome de sua empresa

\begin{tabular}{lcc}
\hline & Características & $\mathbf{( \% )}$ \\
\hline Não & $27 \%$ \\
Sim, não consegui & $47 \%$ \\
Sim, consegui & $26 \%$ \\
\hline Total & $\mathbf{1 0 0 \%}$ \\
\hline
\end{tabular}

Fonte. Autoria Própria (2017).

Questionado se após registro no MEI conseguiu acesso ao crédito, tomar dinheiro emprestado, 47\% responderam "Sim, não consegui", isto é, até tentaram buscar empréstimo, mas não conseguiram, embora que com a empresa formalizada, o Empreendedor Individual tem a possibilidade de abrir uma conta corrente pessoa jurídica, que possibilita o acesso a créditos, empréstimos com juros mais baixos e acessíveis. Segundo Feijó e Silva (2009) com a formalização, o Empreendedor tem condições de obter crédito junto aos bancos, principalmente bancos públicos como o Banco do Brasil e a Caixa Econômica Federal. Esses bancos estão estudando formas de atender às necessidades dos Empreendedores com redução de tarifas e taxas de juros adequadas. 
Tabela 4. Outra fonte de renda, além da sua atividade como MEI

\begin{tabular}{l|c}
\multicolumn{1}{c}{ Características } & $\mathbf{( \% )}$ \\
\hline Não possuo outra fonte de renda & $81 \%$ \\
Tenho emprego & $14 \%$ \\
Recebo bolsa família & $4 \%$ \\
Recebo aposentadoria & $1 \%$ \\
\hline Total & $\mathbf{1 0 0 \%}$ \\
\hline
\end{tabular}

Fonte. Autoria Própria (2017).

Para obter mais conhecimento sobre o microempreendedor individual, procurou-se analisar se eles possuem outra fonte de renda. De acordo com a tabela $4(81 \%)$ dos pesquisados relataram não ter outra fonte de renda, seguido dos que responderam ter outro emprego (14\%). Porém o que mais prevaleceu foi que boa parte sobrevive apenas com os rendimentos gerados pela atividade apresentada nesta pesquisa.

Tabela 5. Principal motivo para ter se registrado como MEI

\begin{tabular}{l|c}
\multicolumn{1}{c}{ Características } & $\mathbf{( \% )}$ \\
\hline Benefícios do INSS (Pagar o INSS) & $30 \%$ \\
Possibilidade de emitir nota fiscal & $18 \%$ \\
Possibilidade de vender para o governo (prefeituras) & $10 \%$ \\
Possibilidade de vender para outras empresas & $15 \%$ \\
Fazer empréstimos & $12 \%$ \\
Facilidade de abrir empresa (baixa burocracia) & $15 \%$ \\
\hline Total & $\mathbf{1 0 0 \%}$ \\
\hline
\end{tabular}

Fonte. Autoria Própria (2017).

Conforme os dados levantados através do questionário aplicado a apresentados na tabela 5 conclui-se que, o que atraiu a maior parte dos trabalhadores a se inscrever no MEI foi a cobertura previdenciária, pois na qualidade de segurado pode usufruir dos auxílios do INSS (30\%); seguidos da possibilidade de emitir nota fiscal (18\%), possibilidade de vender para outras empresas e facilidade de abrir empresa ambas as respostas (15\%).

Em pesquisa apresentada em 2014 pelo SEBRAE, um dos benefícios ainda não utilizados por muitos trabalhadores é a possibilidade de venda de serviços e produtos para o governo, um mecanismo da Lei 128/2008, indica que o governo tem preferência para MEI em licitações.

Ao serem questionados sobre ajuda para se formalizar no MEI (84\%) responderam que receberam ajuda do SEBRAE, (12\%) não receberam nenhum apoio e (4\%) do contador.

A Federação Nacional das Empresas de Serviços Contábeis e das Empresas de Assessoramento, Perícias, Informações e Pesquisas (FENACON) disponibiliza em seu site uma lista detalhada por cidade com os escritórios de contabilidade que estão disponíveis para ajudar os MEI no processo de formalização e na primeira declaração anual, serviços totalmente gratuitos. Esta lista possui endereço, telefone, o nome da empresa, o que o MEI precisa para encontrar com facilidade estes escritórios. 
Tabela 6. Teve dificuldade com alguma das obrigações como MEI

\begin{tabular}{l|c}
\hline \multicolumn{1}{c}{ Características } & $\mathbf{( \% )}$ \\
\hline Fazer os pagamentos em dia & $30 \%$ \\
Fazer declaração de imposto de renda & $24 \%$ \\
Obter o alvará de funcionamento & $32 \%$ \\
Nenhuma dificuldade & $14 \%$ \\
\hline Total & $\mathbf{1 0 0 \%}$ \\
\hline
\end{tabular}

Fonte. Autoria Própria (2017).

De acordo com a tabela 6 obter o alvará de funcionamento (32\%), seguido de (30\%) fazer pagamentos em dia; fazer declaração de imposto de renda (24\%) e (14\%) não encontraram nenhuma dificuldade nas obrigações.

O processo para requerer alvará de funcionamento para MEI na prefeitura de Sobral é o mesmo que para as demais empresas, o que diferencia é que para o MEI o primeiro ano não é cobrado as taxas, o fiscal vai até o local e verifica se está em condições para atender ao público.

Tabela 7. Percebeu mudanças no seu negócio após a formalização como MEI

\begin{tabular}{lc}
\hline \multicolumn{1}{c}{ Características } & $\mathbf{( \% )}$ \\
\hline Sim & $84 \%$ \\
Não & $16 \%$ \\
\hline Total & $\mathbf{1 0 0 \%}$
\end{tabular}

Fonte. Autoria Própria (2017).

A tabela 7 mostra que (84\%) dos pesquisados consideram que com a formalização houve mudanças em quatro aspectos importantes ligados ao negócio, como o aumento do faturamento, melhores condições de compra, ampliação e possibilidade de venda para o governo, elevação da frequência de vendas para outras empresas. O aumento das vendas é muito significativo para a maioria dos microempreendedores, após a formalização.

\section{Considerações Finais}

O objetivo do presente estudo foi analisar quais os principais benefícios que os trabalhadores informais recebem através da formalização como microempreendedor individual. Por meio de uma pesquisa exploratória, com levantamento de dados através de questionário (pesquisa direta), foram entrevistados 70 Microempreendedores Individuais inscritos no município de Sobral-CE, no ano de 2017. 
Dentre os principais resultados do estudo destaca-se que: $56 \%$ dos entrevistados são do sexo feminino, baixo nível de escolaridade (39\% com ensino médio completo), atuando no setor de comércio e serviços, faturamento mensal (30\%) entre 4001 a 5000 mil reais; sendo a atividade exercida em sua própria residência (38\%).

Dentre os principais motivos de adesão ao programa observou-se que $30 \%$ buscaram dentre os principais benefícios da formalização das empresas a cobertura previdenciária, pois na qualidade de segurado pode usufruir dos auxílios do INSS (30\%); seguidos da possibilidade de emitir nota fiscal (18\%), possibilidade de vender para outras empresas e facilidade de abrir empresa ambas as respostas (15\%), fazer empréstimos (12\%) e por ultimo (10\%) possibilidade de vender para o governo. Houve um interesse em aproveitar os benefícios que o programa oferece.

A pesquisa mostrou ainda que $36 \%$ dos entrevistados sobrevivem apenas com os rendimentos gerados pela atividade apresentada nesta pesquisa. Solicitaram financiamento (47\%), porém não conseguiram. Tiveram ajuda para se formalizar pelo SEBRAE (84\%). Dificuldade em obter o alvará de funcionamento (32\%). Recomendariam a formalização no MEI (97\%). Percebeu mudanças no seu negócio após a formalização como MEI (84\%).

Por fim, conclui-se que a principal finalidade do programa lançado pelo governo (MEI), ou seja, tirar da informalidade as pessoas que trabalham por conta própria, conferindo a eles a legalidade de seus negócios, vem sendo bem sucedida no município de Sobral/CE. Prova disso, é o grande número de microempreendedores cadastrados no programa nos últimos anos.

Para trabalhos a serem realizados no futuro referente ao tema, recomendam-se os seguintes tópicos: verificar os impactos do MEI no setor informal no município de Sobral; demonstrar quais as principais dificuldades encontradas pelos Empreendedores Individuais registrados; identificar o perfil dos Empreendedores Individuais formalizados através do MEI em determinado período de tempo, a ser especificado. 


\section{Referencias Bibliográficas}

AMARAL, J.N. Empreendedor individual. Belo Horizonte: SEBRAE / MG, 2012.

ARAÚJO, M.C. Sobrevivência e Mortalidade das Pequenas e Médias Empresas na Cidade de São José dos Campos. 2014. 140F. Dissertação de Mestrado em Administração de Empresas - Universidade de Taubaté.

CÉSAR, N.A; CADE, P.J.L; ALMEIDA, F.M.M; ABREU, E.E; MOURA, R.M. O Micro Empreendedor Individual no Município de Iúna-es: Formalidade X Informalidade. Simpósio de excelência em gestão e tecnologia. IX SEGeT 2012. Disponível em: Acesso em: 10. Set. 2016.

CLEPS, G.D.G. Comércio informal e a produção do espaço urbano em Uberlândia (MG). Sociedade \& Natureza, Uberlândia, V. 21, n. 3, dez. 2009.

CORDEIRO, F.C. Microempreendedor individual: uma visão econômica e tributária brasileira. Blumenau: 2010.

COSTA, M.R. Os controles financeiros como ferramenta do processo de decisão nas micro e pequenas empresas. 2015. 140f. Monografia. Universidade de Taubaté.

DORNELAS, J.C.A. Empreendedorismo corporativo: como ser empreendedor, inovar e se diferenciar na sua empresa. 2. ed. Rio de Janeiro: Elsevier, 2008.

FAGUNDES, Rosival. 2014. Análise do perfil do microempreendedor individual (MEI). Disponivel em: http://www.administradores.com.br/artigos/negocios/analise-do-perfildo-microempreendedor-individual-mei/75010/. Acesso em: 23 de Agosto de 2016.

FEIJÓ, C.A; SILVA, D.B.N; SOUZA, A.C. Quão heterogêneo é o setor informal brasileiro? Uma proposta de classificação de atividades baseada na Ecinf. Revista de economia contemporânea, Rio de Janeiro, V. 13, n. 2, p. 329-354, maio/ago. 2009.

GEM - Global Entrepreneurship Monitor. Motivações para o Empreendedorismo: Necessidade Versus Oportunidade? RAC, Rio de Janeiro, v. 18, n. 3, art. 4, pp. 311-327, Maio/Jun. 2014.

GIL, A.C. Como elaborar projetos de pesquisa. 3 ed. São Paulo: Atlas, 2010.

GUARIDO FILHO, E. R.; MACHADO-DA-SILVA, C. L. A influência de valores ambientais e organizacionais sobre a aprendizagem organizacional na indústria alimentícia paranaense. Revista de Administração Contemporânea, Rio de Janeiro, v. 5, n. 2, p. 33-63, 2014. 
HISRICH, R.D.; PETERS, M,P.; SHEPHERD, A.D. Empreendedorismo. 7 ed. Porto Alegre: Bookman, 2009.

LOPES JÚNIOR, F; MATIAS, A.B. Administração financeira nas empresas de pequeno porte. São Paulo. Editora Manoel Ltda, 2011.

OLIVEIRA, E. M. Empreendedorismo social no Brasil: atual configuração, perspectivas e desafios: notas introdutórias. Revista da FAE, v. 7, p. 9-18, 2014.

PASTORE, J. O pior é a informalidade. (2010). Jornal O Globo, (21/03/2007). Disponível em: 〈http://www.josepastore.com.br/artigos/ti/ti_015.htm >

Acesso em: 10 de Novembro de 2015.

PNAD 2009. Primeiras análises: O mercado de trabalho em 2009. Comunicados do IPEA. $\mathrm{N}^{\circ}$ 62, 23 de setembro de 2010.

PORTAL DO EMPREENDEDOR. Microempreendedor individual. (2015). Disponível em: < www.portaldoempreendedor.com.br >.

Acesso em: 12 de agosto de 2015.

SEBRAE MG. Serviço Brasileiro de Apoio às Micro e Pequenas Empresas. Microempreendedor individual. 2005. Disponível em: < www.sebramg.com.br >. Acesso em: 12 de Agosto de 2015.

SOUZA, K,E. A necessidade da implementação de mudanças estratégicas em empresas brasileiras de pequeno porte. 2013. 115f. Dissertação de Mestrado emEngenharia de Produção - Universidade Federal de Santa Catarina. 